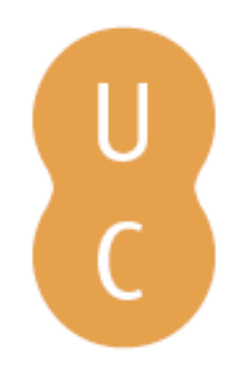

\title{
nombalina
}

\section{Pensar o serviço social hoje: entre mutações, constrangimentos e oportunidades}

Autor(es): $\quad$ Albuquerque, Cristina Pinto; Almeida, Helena; Santos, Clara

Publicado por: Imprensa da Universidade de Coimbra

URL

persistente: URI:http://hdl.handle.net/10316.2/29951

DOI: $\quad$ DOI:http://dx.doi.org/10.14195/978-989-26-0769-6_7

Accessed : $\quad$ 26-Apr-2023 08:18:58

A navegação consulta e descarregamento dos títulos inseridos nas Bibliotecas Digitais UC Digitalis, UC Pombalina e UC Impactum, pressupõem a aceitação plena e sem reservas dos Termos e Condições de Uso destas Bibliotecas Digitais, disponíveis em https://digitalis.uc.pt/pt-pt/termos.

Conforme exposto nos referidos Termos e Condições de Uso, o descarregamento de títulos de acesso restrito requer uma licença válida de autorização devendo o utilizador aceder ao(s) documento(s) a partir de um endereço de IP da instituição detentora da supramencionada licença.

Ao utilizador é apenas permitido o descarregamento para uso pessoal, pelo que o emprego do(s) título(s) descarregado(s) para outro fim, designadamente comercial, carece de autorização do respetivo autor ou editor da obra.

Na medida em que todas as obras da UC Digitalis se encontram protegidas pelo Código do Direito de Autor e Direitos Conexos e demais legislação aplicável, toda a cópia, parcial ou total, deste documento, nos casos em que é legalmente admitida, deverá conter ou fazer-se acompanhar por este aviso.

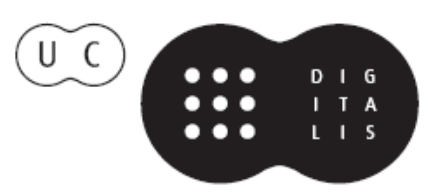




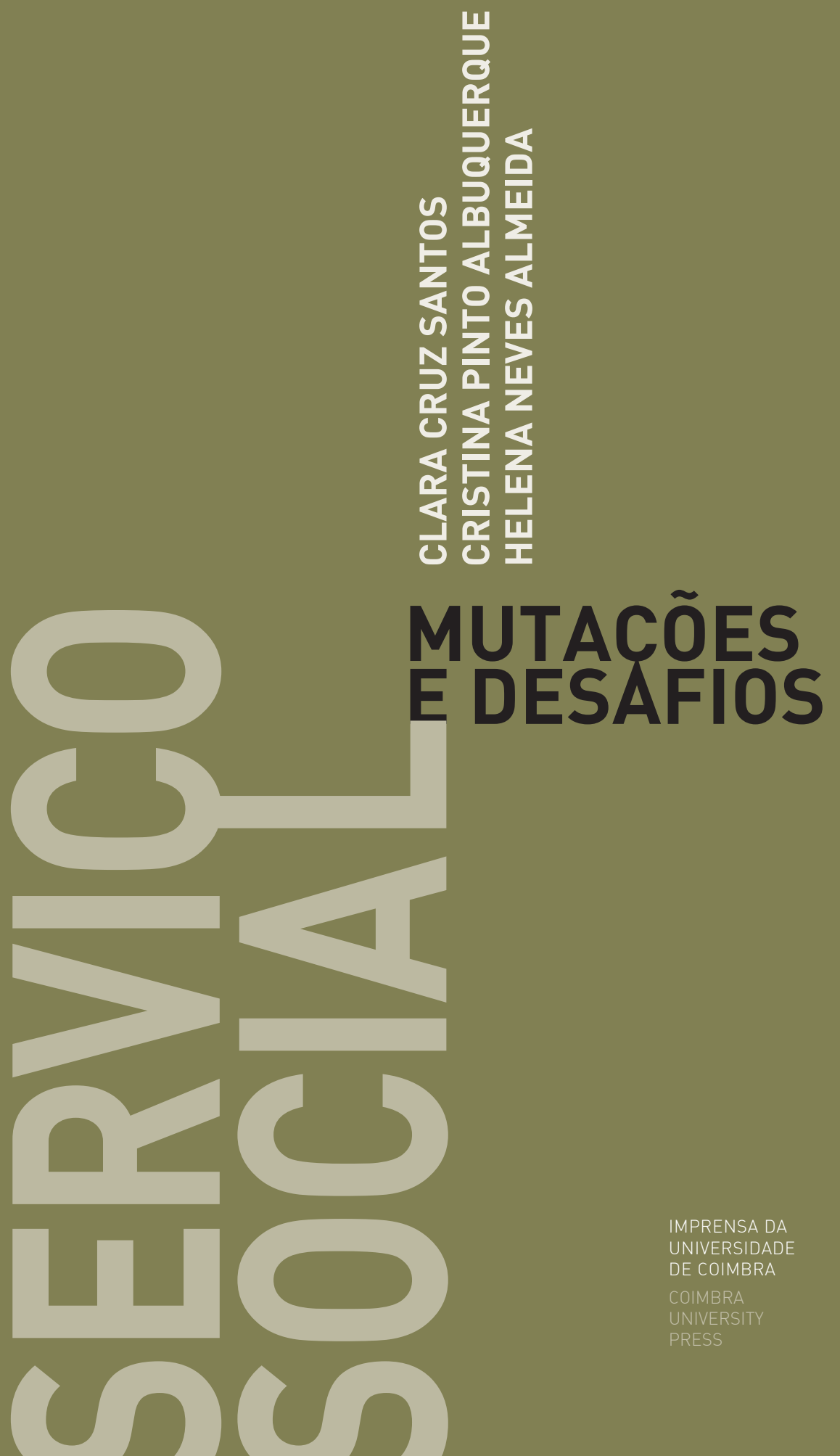


Cristina Pinto Albuquerque

Helena Almeida

Clara Santos

\section{CONCLUSÃO \\ PENSAR O SERVIÇO SOCIAL HOJE: \\ ENTRE MUTAÇÕES, CONSTRANGIMENTOS \\ E OPORTUNIDADES}

Pensar o Serviço Social hoje é sobretudo pensar as condições e os pressupostos inerentes à sua readequação e pertinência na sociedade contemporânea. O compromisso com a mudança, no sentido do desenvolvimento e da justiça social, e a abertura à inovação constituem-se, hoje mais do que nunca, como as pedras de toque de um Serviço Social capaz de se afirmar como elemento estratégico na construção de sociedades alternativas, socioeconomicamente justas e equilibradas.

Como foi salientado ao longo da obra é hoje necessária uma resposta proativa aos desafios sociais e económicos que as sociedades contemporâneas enfrentam; desafios esses que influenciam profundamente as situações problema, as finalidades, os métodos e os processos de trabalho do Serviço Social que, na verdade, foram pensados, definidos e consolidadaos em contextos muito distintos dos atuais.

No quadro da questão social do século XIX, o Serviço Social emergiu (a par da "invenção do próprio Social”, Donzelot, 1984) como o ponto híbrido intermédio entre um Estado de contornos solidaristas e integracionistas, uma lógica social funcionalista e as dimensões da liberdade (cívica e económica) e da igualdade. A ambiguidade decorrente de um tal posicionamento, consubstanciada numa articulação instável e por vezes contraditória entre valores humanitários e responsabilidades político-estatutárias, tem acompanhado o Serviço Social ao longo da sua História. Com efeito, 
o espaço ocupado pelo Serviço Social sempre foi complexo porque relacionado e, em parte, dependente de muitos outros discursos mais estabelecidos, particularmente da lei, da saúde/higiene, da psiquiatria e da educação. Em consequência, definir a natureza, limiares e enquadramentos do Serviço Social, como distintos de outras práticas, sempre foi difícil. Esta dificuldade pode ser uma das chaves definidoras e uma das características estruturais do Serviço Social (Parton, 2000, p. 6).

A constituição do Estado-Providência ao preconizar novas formas de regulação social associadas a uma maior sofisticação e complexificação das sociedades modernas, organicamente constituídas, forneceu ao Serviço Social um conjunto de parâmetros e discursos de enquadramento e de justificação, que traduziram, de forma mais ou menos perene, a razão de ser das suas práticas, e consequentemente, as expectativas sociopolíticas a elas associadas. Nesta ótica, o Serviço Social tem-se constituído sobretudo como o elemento (inter) mediador entre a existência de direitos formalmente estabelecidos e a sua fruição efetiva, especialmente pelas populações vulneráveis e excluídas, mas também, entre as diversas instâncias e agentes, quer do domínio público, quer do domínio privado e voluntário, e os discursos que os constituem. Consagrar-se-ia, assim, o pressuposto de uma sociedade organicamente fundamentada e mais ou menos harmoniosa e normalizada. Para tal, os sistemas modernos de regulação enfatizaram a lógica categorial e previsional, decorrendo da aplicação de um conjunto de pressupostos científicos e estatísticos capazes de dotar a prática de uma maior objetividade e uniformização.

Neste contexto, os discursos técnico e científico, fortemente ancorados na Modernidade, constituíram-se como discursos legitimantes das práticas de Serviço Social, justificadas por pressupostos de perfetibilidade dos seres humanos e de progressividade social e económica. Como referencia Nigel Parton (2000, p. 7),

a contingência foi descoberta em conjunto com o reconhecimento de que as coisas podem ser regulares, repetíveis e previsíveis, logo ordenadas. A visão dos políticos agregou-se às práticas de profissionais e cientistas para melhorar o mundo. A visão era a de uma harmonia hierarquizada refletida nas 
premissas incontestadas e incontestáveis da razão. As tensões, incertezas e mesmo contradições inerentes aos diferentes propósitos e procedimentos eram, assim, parcialmente ocultadas ou sujeitas a uma lógica de racionalização.

As funções providenciais e universalizantes subjacentes aos serviços sociais justificaram, neste âmbito, o desenvolvimento de práticas capazes de efetivar tais propósitos, pela tradução diagnóstica dos problemas e pela operacionalização de mecanismos e dispositivos, eles próprios tradutores de diversas contradições intrínsecas, entre dinâmicas, princípios ou problemas estruturais, e lógicas de resposta muitas vezes individualizadas, centradas nos efeitos e conjunturalmente delineadas e/ou desconectadas.

A par de uma crítica, iniciada nos anos setenta do século XX, em torno da inoperacionalidade, perdularidade e potencial excludente dos serviços de ação social, emerge uma contestação, em diversos quadrantes, do Serviço Social e dos propósitos de controlo que lhe estariam subjacentes. Se durante os anos de crescimento e de centralidade do Estado-Providência keynesiano a justificação pública do Serviço Social decorria da capacidade para estabelecer pontos de contacto entre a margem e o centro, atualmente apela-se sobretudo à reconstrução de elos sociais no âmago de sociedades "sem centro" e à discussão contínua e plural do próprio conceito de norma e de participação, confrontando a lógica hierárquica "topo-base" pela relação cooperativa "base-topo".

Assim sendo, no momento presente, um novo paradigma começa a evidenciar-se associado com a complexidade de sociedades globais, imprevisíveis e tecnológicas. Os pressupostos associados à eficácia, à eficiência, à mensurabilidade e à visibilidade e rapidez na obtenção de resultados tendem a adquirir relevância, em paralelo com práticas de emergência social (e de uma certa permanência na impossibilidade), ou de práticas e iniciativas de inovação social e/ou de mobilização coletiva para a mudança. Neste contexto são relevantes, nomeadamente, os riscos, salientados por diversos autores, de uma possível focalização das práticas em dois pólos (pelo menos aparentemente) opostos, ora de "mecanização", ora de "psicologização" das finalidades e processos de trabalho nas organizações e projetos sociais. A diversidade e complexidade das práticas incrementa-se pois nestes novos cenários sociopolíticos, potenciando, em contraponto, a possibilidade de uma maior indizibilidade 
e sincretismo e como tal colocando sob bases renovadas o debate clássico sobre o espaço profissional e as fontes de legitimidade do Serviço Social.

$\mathrm{Na}$ verdade, os constrangimentos e desafios com que o Serviço Social hoje se confronta, decorrentes de mudanças, profundas e multifacetadas, nos domínios social, económico, político e axiológico, não deixam de comportar, em paralelo, novas, ou renovadas, possibilidades e alternativas de readequação, a nível de finalidades, de procuras, de modelos, de competências, de processos de trabalho e de expectativas.

A inovação social constitui-se, assim, simultaneamente, como uma necessidade e uma oportunidade para a efetivação e consolidação das reais finalidades do Serviço Social, atualmente associadas a processos de autodeterminação, de promoção de oportunidades, de desenvolvimento pessoal, social e económico, em suma de Justiça Social e de Cidadania. A "revolução coperniciana”, em curso ou a operar no Serviço Social contemporâneo, coloca em destaque, desde logo, a necessidade de práticas mais políticas, sistemáticas, estratégicas e analíticas, na senda da rutura com o paradigma da ação imediata centrada no problema e na ideia de défice.

Neste contexto, partilhamos a conceção de Jean-François Garnier de que o Serviço Social não vivencia atualmente uma desprofissionalização, mas antes, um processo de redescoberta e de afirmação de um sentido ontológico ligado à restauração de processos de "reafiliação social". Como afirma o autor (Garnier, 1999, p. 293),

quando o político interroga o profissional, não é de um ponto de vista do sentido, mas do ponto de vista do seu lugar na estrutura jurídico-administrativa. Quando se fala de legitimidade e de reconhecimento, não é em termos de Serviço Social, mas em termos de competências e de instrumentos. Ora, não existem limites para a construção de instrumentos e as competências referem-se ao Serviço Social e não o inverso

São, pois, os processos que adquirem centralidade. A relevância da reflexão que procurámos consubstanciar ao longo do presente livro radicou, assim, sobretudo na necessidade de reposicionar e de reconstituir, na atualidade, referenciais e formas de agregação sociopolítica capazes de dotar de sentido 
a vivência coletiva. A compreensão do mundo atual exige de facto, mais do que em qualquer outra época histórica, a consideração da necessária interdependência entre passado, presente e futuro, assumindo que o presente não é somente o contemporâneo, mas é também um produto de uma herança; uma continuidade seletiva do que foi desenvolvido e aprendido no passado e que se projeta no presente e no futuro.

O enfraquecimento atual das pertenças, os processos complexos de desagregação da coesão social, o desmembramento ou insuficiência dos mecanismos tradicionais de integração e de regulação, apelam à redefinição do sentido das sociedades democráticas e à ponderação dos pressupostos de um novo contrato social. O défice profundo que hoje vivenciamos parece resultar, sobretudo, da fricção entre um ideal de promoção social herdado e a multiplicação de situações de exclusão e desigualdade, e entre o projeto integrador inerente à sociedade salarial e as situações atuais de desqualificação massiva. Neste contexto, é a própria conceção do Social que começa a ser questionada a partir das raízes profundas da sociedade e das bases de preservação, ou de transformação, de princípios, conceitos, técnicas e procedimentos capazes de produzir novos compromissos produtores de um futuro e de um imaginário comuns. Como percecionar, neste quadro, as noções de responsabilidade e de solidariedade? Por outras palavras, como "fazer sociedade" objetivando o direito à dignidade, à utilidade social, à visibilização e ao reconhecimento num registo público. Como sublinham Guy Roustang e outros (1996), ainda que nos tenhamos habituado a pensar o progresso como um processo contínuo e virtuoso de emancipação material e cultural dos indivíduos, a prioridade atual radica antes no reencontro do sentido do bem comum e no estabelecimento de um novo contrato social. Neste contexto em mutação, a atitude perante o conhecimento e a permanente interligação entre este e a realidade objetiva e subjetiva configuram requisitos para um debate aberto sobre as questões da legitimidade e da identidade profissional do Serviço Social.

A nova lógica de intervenção que se impõe neste âmbito decorre, por um lado, de um outro nível de perceção comum das pertenças e de execução das solidariedades, dando forma à manifestação de um sentimento de pertença solidária, e, por outro, de uma mudança (na verdade ainda não 
totalmente efetivada) na leitura da sociedade, leitura essa doravante "topológica", para utilizarmos a linguagem de Jacques Donzelot (1996). Isto significa que a localização, a abrangência e o sentido dos problemas atuais apela ao desenvolvimento e ao aproveitamento de solidariedades concretas segundo perímetros concêntricos e não já segundo uma linha horizontal ligando diferentes grupos sociais e profissionais.

Face à rarefação de fontes de identidade e integração, face ao necessário redimensionamento de modelos sociais e políticos é preciso desenvolver práticas que permitam a restauração da interioridade, o impulsionar de redes de solidariedade (formais e informais), a organização e o envolvimento/implicação de parceiros diversificados, a consciencialização das potencialidades e limites de cada ator, a revivificação da identidade e dignidade individuais, grupais e comunitárias, questionando, quer discursos nostálgicos de retorno ao passado, quer discursos catastrofistas de inexistência de futuro. A implicação emerge neste quadro como uma prova concetual e operativa híbrida, permitindo traduzir a ideia de disseminação e partilha do poder, ou seja, o reconhecimento de agentes e parceiros portadores de lógicas e interesses diversos posicionados em "mesas alargadas de concertação". A lógica implicacionista coloca no âmago da análise a interpretação e a conexão. É através da palavra, do relacional, que os mecanismos da ação se exprimem e que as verdades são interpretadas e traduzidas.

Nesta perspetiva, é essencialmente o domínio do poder, da estandardização e formalismo alienante, do racionalismo técnico, encerrado em "torres de marfim" pseudo legitimantes, das pretensões ao domínio de uma verdade única e irredutível, que precisam de ser questionadas criticamente, sem cair num relativismo absoluto.

As situações atuais, cada vez mais relativizadas, numa verdadeira anarquia dos destinos, contribuem para uma "nova opacidade" (Habermas, 1985) e ilegibilidade do social, colocando radicalmente em causa os princípios igualitários. Se a legitimação de tais princípios tem consistido na compensação do peso do passado, por forma a tornar menos desiguais as condições do futuro, a perceção de tal legitimidade é radicalmente questionada a partir do momento em que o projeto de futuro se esbate e o presente adquire, numa sociedade precarizada, um estatuto privilegiado. 
Trata-se, assim, fundamentalmente, de readequar o princípio da responsabilidade, acedendo ao debate político-social e ao posicionamento moral por referência aos domínios nos quais a sociedade entende dever promover a igualdade. Consubstancia-se, pois, a sociedade que Nicolas Le-Strat (1996) apelida de "pós disciplinar", promovendo um movimento permanente de revalidação daquilo que é e daquilo que deve permanecer e, como tal, relativizando progressivamente a ação da norma, sem deixar de introduzir as necessárias e adequadas adaptações e mudanças. Fala-se por isso de um dever de iniciativa e de novas solidariedades, reconstitutivas da dimensão ética da cidadania social.

Nesta perspetiva, afigura-se essencial uma abordagem mais política da solidariedade; uma abordagem que permita repensar, não somente a conceção dos direitos sociais como direitos compensatórios, mas as próprias bases do contrato social democrático e dos seus fundamentos de Justiça, Liberdade, Segurança e Bem-Estar. A missão do Estado, neste sentido, deixa de ser a orquestração da solidariedade e da economia, para passar a ser essencialmente a produção da própria sociedade e da sua coesão. Para tal, cabe-lhe: assegurar os mecanismos e os critérios de equidade subjacentes à negociação da pertença e permanência dos indivíduos nos contextos económico-sociais; constituir-se como um parceiro entre parceiros, conjurando os efeitos da decomposição do tecido social; e sobretudo afirmar-se como produtor de futuro, impulsionando e desbravando caminhos, que permitam aos agentes sociais reconstituir laços societais fraturados e pontos de referência sólidos para uma vivência coletiva regenerada.

Esta nova forma de percecionar e refundar o Social, que procurámos esboçar brevemente, produz inequivocamente implicações profundas sobre a cultura profissional do Serviço Social. É possível desde logo destacar-se um triplo desafio (Loubat, 1996): o de comunicar, não somente numa aceção mais ou menos simplista de troca de informação, mas, no sentido de reconstituição de elos e de pertença por via da palavra; o de avaliar os serviços prestados, tendo subjacentes preocupações de racionalização e eficácia; o de gerir e construir recursos.

Porém, estes aspetos não esgotam a pluridimensionalidade dos desafios que hoje se colocam ao Serviço Social, e que alocam exigências concetuais e 
operativas ao nível das finalidades, dos públicos, das competências e dos processos de trabalho. O agir profissional é complexo, dada a interdependência dos fatores analíticos e vivenciais associados à procura social, a multidimensionalidade da ação empreendida e dos contextos de referência.

Pensar o Serviço Social hoje não se compadece com as exigências processuais e os pressupostos teóricos de uma intervenção centrada no aqui e agora, imediatista e reprodutora do status quo tanto dos públicos-alvo, como das organizações e dos parceiros. Imaginemos um torneio de xadrês onde participam vários jogadores, mas as regras do jogo se alteram, as peças posicionam-se à partida de forma diferente, os jogadores mostram-se submissos e conformados, sensíveis às alterações circunstanciais e externas, e onde se instala a desconfiança e a dependência de quem os comanda. Ousaríamos pensar tratar-se de um jogo de xadrez? Certamente que não, na medida em que este jogo está alicerçado em 3 pilares fundamentais: conhecimento das regras, autonomia e liberdade para agir e pensamento estratégico. Não se trata apenas de saber as regras de movimento de cada peça, pois cada movimento implica outras dinâmicas, nos jogadores, no processo de jogo, no seu desenvolvimento e nos resultados. Se aplicarmos esta lógica de jogo ao domínio social e substituirmos cada uma das peças pelas principais áreas de intervenção dos Assistentes Sociais (educação, saúde, justiça, trabalho, segurança social, poder local), depressa chegaremos à conclusão de que as regras se têm vindo a alterar de forma constante e em todas as áreas, dando visibilidade a uma perspetiva sumativa de políticas, medidas e recursos, onde a autonomia e a liberdade para agir se confina cada vez mais ao imediato e ao pressuposto da intervenção ou iniciativa "mínima", e à ausência de perspetiva estratégica em contextos de mudança. Como salientam Karen Postle e Mark Lymbery (2007, p. 266) as práticas de gestão social economicistas, a diminuição do valor atribuído às competências de avaliação e comunicação, bem como a utilização do self e a rápida mudança dos contextos organizacionais constituem algumas das ameaças ao Serviço Social na atualidade, mas também podem constituir-se como eixos de novas possibilidades de ação. É por isso importante repensar e readaptar métodos de gestão do trabalho usando estrategicamente por exemplo os instrumentos proporcionados pelas tecnologias da informação e da comunicação, "da melhor forma para uma melhor 
prática" (Hill \& Shaw, 2011), sem perder os valores centrais da profissão. As novas tecnologias podem de facto incrementar o potencial de construção de novas respostas e a definição de estratégias inovadoras para a identificação das causas de problemas sociais, de avaliação de impactes de intervenções e de políticas, de criação de novos espaços públicos de participação abertos a um maior número de cidadãos, de partilha de dados e de experiências entre profissionais e de "hibridização" de análises e de respostas, desta forma mais holísticas e reflexivas.

Nas sociedades atuais, incertas e complexas, reclamando uma nova compreensão e intervenção face a necessidades prementes e diversificadas, tais processos de abertura a lógicas inovadoras torna-se não apenas importante mas essencial. As formas de adaptação, ou de resistência, às novas condições condicionarão inevitavelmente o papel que o Serviço Social está capacitado para desempenhar, agora e no futuro, exercendo influência sobre as questões políticas, sociais e económicas fundamentais.

\section{Referências}

Beech, R. \& Roberts, D. (2008). Assistive technology and older people. SCIE web-site. Briefing paper, 28. Consultado em 20 março, 2011, em: http://www.scie.org.uk/publications/briefings/briefing28.

Donzelot, J. (1984). L’Invention du Social. Essai sur le déclin des passions politiques. Paris: Librairie Arthème Fayard.

Donzelot, J. (1996). L’Avenir du Social. Esprit, 219, pp. 58-81.

Garnier, ARNIER J.F. (1999)., Assistante Sociale: pour la redéfinition d'un métier. Essai anthroposociologique sur le service social., Paris: L'Harmattan., 1999, p. 293

Habermas, J. (1985). A nova opacidade: a crise do Estado-Providência e o esgotamento das energias utópicas. Separata da Revista Comunicação e Linguagens, pp. 115-128.

Hill, A. \& Shaw, I. (2011). Social Work \& ICT. London: Sage Publications Ltd.

Langan, J. (2009). Mental health, risk communication and data quality in the electronic age. British Journal of Social Work, 39(3), 467-487.

Le-Strat, P. N. (1996). L'Implication, une nouvelle base de l'intervention sociale. Paris: L'Harmattan.

Lymbery, M and Postle, K.(Ed.) (2007). Social Work. A Companion to Learning. London: sage Publications.

Loubat, J.R.(1996). Vers la mediation et le conseil sociaux. In J. L. Martinet (dir). Les Éducateurs aujourd'hui. Paris: Dunod. 
Parton, N. (2000)., "Social theory, social change and social work. An introduction." In N. Parton (ed.)., Social Theory, Social Change and Social Work., London: Routledge., The State of Welfare Series, 2000 (1st edition: 1996), p. 6

Roustang, G, Laville, J.L., Eme, B., Mothé, D., Perret, B. (1996). Vers un nouveau contrat social. Paris: Desclée de Brouwner. 
SÉRIE ENSINO

IMPRENSA DA UNIVERSIDADE DE COIMBRA

COIMBRA UNIVERSITY PRESS

2013

$\mathbf{U}$

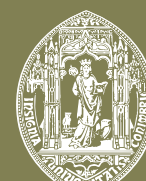

$\frac{\mathrm{I}}{\mathrm{U}}$

C • 